\title{
Impact of Running a Behavior Therapy Room for Various Categories of Urinary Incontinence Cases in Different Age Groups in Obstetrics-Gynecology Outpatient Department of a Tertiary Care Hospital
}

\author{
${ }^{1}$ Tejinder Kaur, ${ }^{2}$ Puja Dudeja, ${ }^{3}$ Meenakshi Sharma, ${ }^{4}$ Vanita Jain, ${ }^{5}$ Amarjeet Singh
}

\begin{abstract}
Introduction: Urinary incontinence (UI) affects $>60 \%$ women. Its management is simple with the use of Kegel exercises. However, very few studies have been done in India about this problem and its solution.
\end{abstract}

Objective: To assess the impact of running a behavior therapy room (BTR) for various categories of UI cases in different age groups in obstetrics gynecology outpatient department (OBG-OPD) of a tertiary care hospital.

Materials and methods: Patients of UI were referred from gynecology OPD to BTR. There was trained staff available in BTR to teach Kegel exercises and related behavior therapy to the patients. Records of the patients were maintained. Follow-up was done through phone calls and personal visits of UI patients.

Results: A total of 251 cases were registered in BTR over 2 years. Overall 126 patients got relief from urine incontinence and prolapse of pelvic floor organs after BT.

Conclusion: Establishment of a separate room (BTR) with trained staff can be done in OBG department to teach Kegel exercises and to provide relief to women suffering from $\mathrm{UI}$ and pelvic organ prolapse (POP).

Recommendation: Behavior therapy room should be established in gynecology OPDs of all hospitals.

Keywords: Behavior therapy room, Obstetrics and gynecology, Outpatient department, Urine incontinence, Pelvic organ prolapse, Quality of life, Urinary tract infections, Department of biotechnology, Impact incontinence questionnaire, Stress urinary incontinence, Urge urinary incontinence, Mixed urine incontinence, Pelvic floor muscles, Odds ratio.

How to cite this article: Kaur T, Dudeja P, Sharma M, Jain V, Singh A. Impact of Running a Behavior Therapy Room for Various Categories of Urinary Incontinence Cases in Different Age Groups in Obstetrics-Gynecology Outpatient Department of a Tertiary Care Hospital. J Postgrad Med Edu Res 2014;48(4):159-163.

\footnotetext{
${ }^{1}$ Research Fellow, ${ }^{2,3} \mathrm{PhD}$ Scholar, ${ }^{4,5}$ Professor

1-3,5 Department of Community Medicine, Postgraduate Institute of Medical Education and Research, Chandigarh, India

${ }^{4}$ Department of Obstetrics and Gynecology, Postgraduate Institute of Medical Education and Research, Chandigarh, India

Corresponding Author: Tejinder Kaur, Research Fellow Department of Community Medicine, Postgraduate Institute of Medical Education and Research, Chandigarh, India, Phone: 91-9815398004, e-mail: maytejinder@gmail.com
}

Source of support: Department of Biotechnology, New Delhi, India

Conflict of interest: None

\section{INTRODUCTION}

Urinary incontinence (UI) is a common and distressing medical condition, severely affecting quality of life (QOL) ${ }^{1,2}$ Often social interactions of such women are adversely affected. Women avoid social events, work and sexual activities. It may even lead to feelings of shame and depression. Urinary tract infections (UTIs), skin problems, such as rashes, infections and sores, are the common problems which are reported by women with UI. These comorbid conditions are due to constantly wet skin. ${ }^{1}$ Increased costs and efforts for washing the clothes and linen and healthcare adds to the adverse consequences of this condition due to the economic burden of this problem. ${ }^{1,2}$ Women hesitate to seek help or report symptoms to medical practitioners due to the embarrassing and culturally sensitive nature of this condition. The problem is usually under reported. ${ }^{3}$ Most women do not seek medical attention and treatment ${ }^{3}$ for this condition. Women feel quite embarrassed to seek help and 'just live with' the condition. They take it as a 'normal' part of aging and having children. They do not openly or publicly discuss about UI. ${ }^{4,5}$ It affects at least one-third of women. ${ }^{6}$

Still, UI consultation rate is low in the North Indian Women. ${ }^{4}$ The prevalence of UI by type in each racial/ ethnic group, adjusted for age for Asian women, was $18.3 \%, 23 \%$ in Black women, $31.1 \%$ in Hispanic women and, in White women, it was found to be $21.2 \%$. But prevalence of only stress UI peaks around menopause transitional phase. ${ }^{7,8}$ While stress and urge UI increases with age. Urge UI (UOI) was related to age, childhood enuresis, higher body mass index (BMI), poor psychological health. ${ }^{8}$ In young women, the prevalence of UI is usually low. ${ }^{9}$

Many of the cases of UI can be managed with the help of Kegel exercises and bladder training (behavior therapy). Still, obstetrics and gynecology clinics do not 
commonly advocate this mode of therapy to UI patients. Against this background, present study was done with an objective to document the impact of running a behavior therapy room (BTR) for various categories of UI cases in different age groups in obstetrics gynecology outpatient department (OBG-OPD) of a tertiary care hospital.

\section{MATERIALS AND METHODS}

The present study was conducted during April 2010 to June 2012 in Obstetrics and Gynecology (OBG) department of a tertiary care hospital of North India. A behavior therapy room was established in the OBG-OPD as a part of 2 years of DBT (Dept of Biotechnology) Project. Separate female staff was recruited to run the BTR. The staff was given 2 weeks training at the beginning of the study.

Patients of UI and pelvic organ prolapse (POP) were referred from OBG-OPD to BTR. They were registered separately in BTR for the study. Informed consent was taken. A record of brief case history, sociodemographic profile, incontinence, its types and severity, obstetric history, risk factors for incontinence, and impact of UI on QOL was taken from every patient. The patients with third degree of POP were excluded from the study.

A subset of patients were taken for pad test. Pad test was done to assess quantification of improvement in some randomly selected and willing cases. The degree of UI was quantified using baseline and follows-up performa, pad test and impact incontinence questionnaire (IIQ). The assessment of degree of leakage was done by using a formula, i.e. degree of incontinence $\left(A^{*} B\right)$, where leakage of urine $=\mathrm{A}$ (never $=1,1$ day per week $=2,2-3$ days per week $=$ 3 , almost daily $=4) \times$ volume of leakage of urine $=\mathrm{B}(1-2$ drops $=1$, enough to wet underwear $=2$ ). Grading of leakage was done as: mild leakage score $=1-2$, moderate leakage score $=3-4$, severe leakage score $\geq 4$.

Severity and quantification of UI measured through pad test. The impact of UI on daily activities, social interaction and self perception was calculated through impact incontinence questionnaire. It (IIQ) had three main components: daily activities, social interaction and self perception. It consists of 26 items. Every item has four options. The options are ranked as $0=$ not at all, $1=$ slightly, 2 = moderately, 3 = greatly. The IIQ permissible highest score is 78 and lowest score is 26.
Kegel exercises were taught to individual patients over 15 to 20 minutes. A booklet on conservative management of UI and POP was given to the patients free of cost in the language they desired (English, Hindi or Punjabi). The booklets contained the details of Kegel exercises, bladder training and lifestyle changes along with pictorial charts. The booklets also covered the behavior therapy aspects. Follow-up was done for all patients in the OBG-OPD on subsequent visits. Loss to follow-up cases was contacted through phone calls. Verbatim data was recorded on the first visit and then after 2 months of follow-up. A semistructured questionnaire for patients was also filled by behavior therapist. A subset of randomly selected and willing patients was taken for pad test to quantify the improvement in leakage. The verbatim responses of individual cases were recorded in BTR. The analysis was done by using Chi-square for trends on Epi Info version 3.5.1. The Odds ratio was calculated for different age groups for UI and POP. Textual analysis was recorded for verbatim data.

\section{RESULTS}

Table 1 shows that bulk of the UI cases of all categories were above the age groups of 30 years $(75 \%)$ as compared to $21.5 \%$ in younger age groups.

The Table 2 shows the proportion of the patients in various categories of UI and their response to UI treatment. Overall 251 patients with UI were recruited in BTR during April 2011 to Sep 2012. Half of the patients got relief with Kegel exercises.

Table 3 shows that the women who belong to 10 to 30 years age group in all categories of UI, i.e. stress, urge, mixed, got more relief than the higher age groups except for women with prolapse and urge incontinence in the age groups of 31 to 60 and $>60$. The latter group showed more improvement in their problem with the modification of behavior with Kegel exercises in their lifestyle. The data revealed that the middle age group with (31-60 years) women also showed 50\% improvement in the problem with Kegel exercises. But, elderly women, i.e. $>60$ years age group showed less improvement even by doing Kegel exercises. The data showed that stress urinary incontinence (SUI) patients got more relief than

Table 1: Registration of urinary incontinence cases by age in OBG-OPD

\begin{tabular}{|c|c|c|c|c|c|c|c|}
\hline \multirow[t]{2}{*}{ Age (yrs) } & \multicolumn{3}{|c|}{ Type of incontinence cases } & \multicolumn{3}{|c|}{ Type of prolapse cases } & \multirow[t]{2}{*}{ Total (\%) } \\
\hline & Stress (\%) & Urge (\%) & Mixed (\%) & POP with SUI (\%) & POP with UUI (\%) & POP with MUI (\%) & \\
\hline $10-30$ & $4(75)$ & $3(66)$ & $5(80)$ & $11(72)$ & $2(50)$ & $2(5)$ & $27(21.51)$ \\
\hline $31-60$ & $61(52)$ & $23(47)$ & $38(60)$ & $39(48)$ & $14(50)$ & $15(46)$ & $190(75)$ \\
\hline$>60$ & $6(16)$ & $3(33)$ & $8(25)$ & $8(12.5)$ & $3(66)$ & $6(16)$ & $34(13.5)$ \\
\hline Total & 71 & 29 & 51 & 58 & 19 & 23 & 251 \\
\hline
\end{tabular}

Patients who were medically examined by gynecologists and referred to BT room if detected for UI and prolapse; SUI: Stress urinary incontinence; UUI: Urge urinary incontinence; MUI: Mixed urinary incontinence 
urge urinary incontinence (UUI). Relief reported in the age group of $>60$ years was less with the advancing age.

Table 4 shows that patients' physical as well as mental health was greatly affected due to UI. Performing heavy work (washing clothes) and travelling more than $30 \mathrm{~min}$ utes were affected due to involuntary leakage of urine in UI patients. Their religious activities are also affected due to UI. Relationships with their husbands were affected due to urine frequency. Many patients reported that their sexual relations with their partners were disturbed due to

Table 2: Impact of BT room consultation on different types of cases of urine incontinence

\begin{tabular}{llll}
\hline Type of incontinence & No. of & \multicolumn{2}{c}{ Reported relief } \\
\cline { 3 - 4 } & patients (\%) & Yes (\%) & No (\%) \\
\hline Stress UI & $71(28.2)$ & $36(50.7)$ & $35(49.3)$ \\
Urge UI & $29(11.5)$ & $14(48.2)$ & $15(51.7)$ \\
Mixed UI & $51(20.3)$ & $29(56.8)$ & $22(43.1)$ \\
Prolapse with SUI & $58(23.1)$ & $28(48.2)$ & $30(51.7)$ \\
Prolapse with UUI & $19(7.5)$ & $10(52.6)$ & $9(47.3)$ \\
Prolapse with MUI & $23(9.16)$ & $9(39.1)$ & $14(60.9)$ \\
\hline Total & 251 & $126(50.1)$ & $125(49.8)$ \\
\hline
\end{tabular}

Table 3: Trends of impact of BT on various categories of $\mathrm{UI}$ in different age groups

\begin{tabular}{|c|c|c|c|c|c|}
\hline \multirow[t]{2}{*}{ Age (years) } & \multicolumn{2}{|c|}{ Relief } & \multirow[t]{2}{*}{ Total } & \multirow[t]{2}{*}{ Odds of relief } & \multirow[t]{2}{*}{$p$-value } \\
\hline & Yes & No & & & \\
\hline \multicolumn{6}{|l|}{ SUI } \\
\hline $10-30$ & 3 & 1 & 4 & 1.00 & $0.05^{\star}$ \\
\hline $31-60$ & 32 & 29 & 61 & 0.37 & \\
\hline$>60$ & 1 & 5 & 6 & 0.07 & \\
\hline \multicolumn{6}{|l|}{ UI } \\
\hline $10-30$ & 2 & 1 & 3 & 1.00 & 0.42 \\
\hline $31-60$ & 11 & 12 & 23 & 0.46 & \\
\hline$>60$ & 1 & 2 & 3 & 0.25 & \\
\hline \multicolumn{6}{|l|}{ MUI } \\
\hline $10-30$ & 4 & 1 & 5 & 1.00 & $0.03^{*}$ \\
\hline $31-60$ & 23 & 15 & 38 & 0.38 & \\
\hline$>60$ & 2 & 6 & 8 & 0.08 & \\
\hline \multicolumn{6}{|l|}{ POP with } \\
\hline $10-30$ & 8 & 3 & 11 & 1.00 & $0.01^{*}$ \\
\hline $31-60$ & 19 & 20 & 39 & 0.36 & \\
\hline$>60$ & 1 & 7 & 8 & 0.05 & \\
\hline \multicolumn{6}{|l|}{$\begin{array}{l}\text { POP with } \\
\text { UUI }\end{array}$} \\
\hline $10-30$ & 1 & 1 & 2 & 1.00 & 0.67 \\
\hline $31-60$ & 7 & 7 & 14 & 2.00 & \\
\hline$>60$ & 2 & 1 & 3 & 2.00 & \\
\hline \multicolumn{6}{|l|}{$\begin{array}{l}\text { POP with } \\
\text { MUI }\end{array}$} \\
\hline $10-30$ & 1 & 1 & 2 & 1.00 & 0.24 \\
\hline $31-60$ & 7 & 8 & 15 & 0.88 & \\
\hline$>60$ & 1 & 5 & 6 & 0.20 & \\
\hline
\end{tabular}

*Significant difference; SUI: stress urine incontinence; UI: Urge incontinence; MUI: Mixed urinary incontinence; POP with SUI: Pelvic organ prolapse with stress urine incontinence; POP with UOI: Pelvic organ prolapse with urge urinary incontinence; POP with MUI: Pelvic organ prolapse with mixed urinary incontinence
UI. The patients of UI always had fear of odor and feeling embarrassed.

Table 5 shows that the patients were affected in their daily activities mentally and physically due to involuntary leakage of urine. Eleven patients out of 24 showed significant results as per IIQ. Pad test were conducted on the UI patients on their first visit. Then, Kegel exercises were taught to all patients. Pad weight was reduced in all the patients in their second and following visits after the performance of Kegel exercises. The objectives and subjective responses of the patients reflected relief in their symptoms of UI.

\section{DISCUSSION}

Our data revealed that UI grossly affected the QOL of patients. ${ }^{1,4,10}$ Incontinence and prolapse affected social life, household work as well as personal relations of affected women. Similar results have been reported in other studies. ${ }^{1,4}$ It also limited the religious activities and travelling of the patients with UI. ${ }^{1,4}$

Table 4: Data on a subset of patients regarding the impact of $U I$ on daily activities, social interaction and self perception as per impact incontinence questionnaire (IIQ) $(n=19)$

\begin{tabular}{|c|c|c|}
\hline \multirow[t]{2}{*}{ Daily activities } & \multicolumn{2}{|c|}{ Impact as per IIQ score } \\
\hline & None & Moderate/great \\
\hline Cooking & 17 & 2 \\
\hline House cleaning & 15 & 4 \\
\hline Washing clothes & 14 & 5 \\
\hline House repair work & 18 & 1 \\
\hline Shopping & 15 & 4 \\
\hline Sleep & 16 & 3 \\
\hline Walking & 15 & 4 \\
\hline Entertainment & 19 & 0 \\
\hline Travel $(<30)$ & 15 & 4 \\
\hline Travel $(>30)$ & 15 & 4 \\
\hline $\begin{array}{l}\text { Visit to place with unknown } \\
\text { restrooms }\end{array}$ & 18 & 1 \\
\hline Vacations & 19 & 0 \\
\hline $\begin{array}{l}\text { Temple/Gurudwara/Church } \\
\text { attendance }\end{array}$ & 15 & 4 \\
\hline Volunteer activity & 18 & 1 \\
\hline \multicolumn{3}{|l|}{ Social interaction } \\
\hline Having friends visit & 16 & 3 \\
\hline Visiting friends/relatives & 14 & 5 \\
\hline $\begin{array}{l}\text { Participating in social activities } \\
\text { outside home }\end{array}$ & 14 & 5 \\
\hline Relationship with friends & 17 & 2 \\
\hline Relationship with family & 17 & 2 \\
\hline Relationship with husband & 12 & 7 \\
\hline Sexual relations & 13 & 6 \\
\hline Way you dress & 15 & 4 \\
\hline \multicolumn{3}{|l|}{ Self perception } \\
\hline Physical health & 14 & 5 \\
\hline Mental health & 13 & 6 \\
\hline Fear of odor & 13 & 6 \\
\hline Fear of embarrassment & 10 & 9 \\
\hline
\end{tabular}

*Highest score 78 and lowest score 26 
Urinary incontinence is a significant health problem in the community which leads to embarrassment. ${ }^{9}$ It curtailed the daily heavy work, social ${ }^{11}$ and sexual activities of the women.

Our data also showed that age affected the prevalence of all the categories of UI. Cases were maximum in the age group of 31 to 60 years. Similar results were reported by Kumari et al. ${ }^{4}$ Others studies also reported the same results. ${ }^{6,7}$ Its prevalence advances with increasing age. ${ }^{7}$ The prevalence of daily UI increases with age, ranging from $34 \%$ in women above 60 years of age in our study to $38 \%$ in an international study. ${ }^{12}$ In young women, the prevalence of incontinence was low, but prevalence peaks around menopausal age. ${ }^{13}$

Higher proportion of UI cases being from the women aged above 30 years is because of the fact that with age the tone of pelvic floor muscles (PFM) gets weaker. Age also affected the degree of relief obtained by UI cases after doing Kegel exercises. Better relief was reported in younger women. ${ }^{14}$ It might have been due to better tone of PFM in younger women. Half of the women in our study became continent after behavior therapy (BT) which is similar to the results of Kumari et al. ${ }^{4}$

Many women having uterine prolapse also presented with UI. Earlier also the data from our institution had
Verbatim response of some patients who got relief:

1. The patient with UI and Frequency of urine said 'Exercise kar rahi hoon and abhi main khush bhi hoon, kafi fark parha hai'. I am doing exercise. I am happy. It has improved a lot. She further said 'mujhe $60 \%$ fark hai, exercise regular karne ki koshish karti hoon' I got $60 \%$ relief. I try to do exercise regularly.

2. The patient with SUI said 'Pehle se bahut farak hai.Meri 12 saal ki bimari theek kar di'. I have improved a lot than before. My 12 years old problem has been cured.

3. The patient with Cystocele, Rectocele said 'Exercise kar rahi huun and kafi aaram lagta hai'. I am performing exercise. I have got relief.

4. The patient with SUI said 'Main bilkul theekh ho gai hoon') I have been totally cured.

5. The patient with Cystocele, Rectocele said 'Haan mein kegel exercises karti huun. Aur exercise karne se farak hai'... Yes I am performing kegel exercises. I got improvement after performing it.

6. The patient with 1st degree Prolapse said 'Maam I am fine. Mein exercise almost daily kar hi leti huun'. Maam I am fine. I am doing exercise almost every day).

7. The patient with 2 nd degree UV Prolapse, Gr 1 rectocele, and Urge Incontinence reported relief as she said'.'Maam mujhe thoda sa farak lagta ha. Maam I got some improvement'.

8. A patient with Descent said 'Din mein ek baar hi karti hoon exercise, thora fark hai, abh din mein 4 baar karungi'. I do exercise once in a day. I got some improvement. Now I will perform exercise four times in a day.

Table 5: Pad test and overall IIQ score on a subset of patients

\begin{tabular}{|c|c|c|c|c|c|}
\hline \multirow[t]{2}{*}{ IIQ score } & \multicolumn{2}{|l|}{ Pad } & \multirow[t]{2}{*}{ Reduction } & \multicolumn{2}{|c|}{ Relief } \\
\hline & Weight before $B T$ & After BT & & Objective & Subjective \\
\hline 31 & 0.165 & 0.112 & 0.053 & Yes & Yes \\
\hline 14 & 0.743 & 0.523 & 0.22 & Yes & Raat ko farak pada hai \\
\hline 2 & 0.273 & 0.220 & 0.053 & Yes & Got relief \\
\hline 21 & 51 & 47 & 4 & Yes & Got relief \\
\hline 13 & 0.64 & 0.62 & 0.02 & Yes & Got improvement \\
\hline 18 & 0.1 & 0 & 0.1 & Yes & Little improvement in health \\
\hline 7 & 9.5 & 9 & 0.5 & Yes & Got relief \\
\hline 3 & 17.8 & 5.2 & 12.6 & Yes & Got some improvement \\
\hline 37 & 0.068 & 0.065 & 0.003 & Yes & No response \\
\hline 31 & 0.168 & 0.150 & 0.018 & Yes & No response \\
\hline 0 & 0.275 & 0.270 & 0.005 & Yes & No response \\
\hline 22 & 1.13 & 1.10 & 0.03 & Yes & Got relieved \\
\hline 8 & 1.9 & 1 & 0.9 & Yes & No response \\
\hline 26 & 16.5 & 16 & 0.5 & Yes & Kafi pharak pad gaya hai \\
\hline 7 & 0.473 & 0.323 & 0.15 & Yes & No response \\
\hline 15 & 0.25 & 0.23 & 0.02 & Yes & Bahut farak hai \\
\hline 11 & 3.3 & 3.1 & 0.2 & Yes & Got improvement \\
\hline 45 & 30.9 & 4.19 & 26.71 & Yes & No response \\
\hline 0 & 6.2 & 5.48 & 0.72 & Yes & Got relief \\
\hline 34 & 20.4 & 0 & 20.4 & Yes & Got relief \\
\hline 0 & 6.4 & 3.6 & 2.8 & Yes & Got improvement \\
\hline 0 & 5.5 & 4.19 & 1.31 & Yes & $\begin{array}{l}\text { Abhi tak koi takleef nahi hai } \\
\text { in hindi }\end{array}$ \\
\hline 0 & 0.5 & 0 & 0.5 & Yes & Kafi farak hai \\
\hline 0 & 1.78 & 0 & 1.78 & Yes & Ab to kafi aaram hai \\
\hline
\end{tabular}

Calculation of leakage of urine of the willing patients in BTR 
reported that more than $80 \%$ of uterine prolapse cases have UI. ${ }^{15,16}$ Many other international studies have also reported association of uterus prolapse with UI and voiding problems. ${ }^{17,18}$

Kegel exercises are the most popular method of treatment for SUI and other type of incontinence as well as for all age groups. ${ }^{19}$ Overall our study also indicated that pelvic floor muscles exercised (PFME), the repetitively selective voluntary contraction and relaxation of specific $\mathrm{PFM}^{20}$ also known as Kegels are effective for both with $\mathrm{UI}^{19}$ or without UI.

Stress incontinence $(71, \mathrm{n}=251)$ emerged as the most common type of UI in our study. Other research studies in India and world have also reported similar results. ${ }^{7,9,14,21}$ In addition, many incontinent women experienced remission of symptoms after behavior therapy. ${ }^{13,22}$

Pelvic floor muscles tone improve faster in younger age than the older age due to weakening of pelvic floor muscles. ${ }^{11}$ In nutshell, both objective and subjective data from our study revealed that behavior therapy was effective in UI cases.

\section{CONCLUSION}

Our findings suggested that Kegel exercises were helpful in treating UI with or without prolapse uterus. This was particularly true for women aged $<60$ years. Hence, BTR can be successfully use to provide relief to women suffering from UI and early prolapse uterus. Future research and prevention efforts should carefully consider behavior therapy as a mechanism to prevent and treat UI in gynecology OPDs.

\section{RECOMMENDATION}

Behavior therapy room should be established in Gynecology OPDs of all hospitals. Special care should be taken for women aged $>60$ years.

\section{ACKNOWLEDGMENT}

We want to acknowledge the Department of Biotechnology, New Delhi, India to provide us financial support for this project.

\section{REFERENCES}

1. Bodhare TN, Valsangkar S, Bele SD. An epidemiological study of urinary incontinence and its impact on quality of life among women aged 35 years and above in a rural area. Indian J Urol 2010;26(3):353-358.

2. Currie CJ, McEwan P, Poole CD, Odeyemi IA, Datta SN, Morgan CL. The impact of the overactive bladder on healthrelated utility and quality of life. BJU Int 2006;97(6):1267-1272.

3. Burgio KL, Ives DG, Locher JL, Arena VC, Kuller LH. Treatment seeking for urinary incontinence in older adults. J Am Geriatr Soc 1994;42(2):208-212.
4. Kumari S, Singh AJ, Jain V. Treatment seeking behavior for urinary incontinence among north Indian women. Indian J Med Sci 2008;62(9):352-356.

5. Magon N, Kalra B, MalikS, Chauhan M. Stress urinary incontinence: what, when, why, and then what. J Midlife Health 2011;2(2):57-64.

6. Thom DH, van den Eeden SK, Ragins AI, Wassel-Fyr C, Vittinghof E, Subak LL, Brown JS. Differences in prevalence of urinary incontinence by race/ethnicity. J Urol 2006;175(1): 259-264.

7. Victor WN. The prevalence of urinary incontinenece. Rec Urol 2001;3(Suppl):S2-S6.

8. Mishra GD, Cardozo L, Kuh D. Menopausal transition and the risk of urinary incontinence: results from a British prospective cohort. Int BJU 2010;108(8):1170-1175.

9. Kumari S. Impact of behavioural therapy training package on occurance and severity of urinary incontinenece among adult women of a residential area of UT Chandigarh: PhD thesis, Department of Community Medicine, PGIMER, Chandigarh October 2007.

10. Papanicolau S, Hunskaar S, Lose G, Sykes D. Assessment of bothersomeness and impact or quality of life of urinary incontinence in women in France, Germany, Spain and the UK. Br J Urol Int 2005;96(6):831-838.

11. Walker GJ, Gunasekera P. Pelvic organ prolapse and incontinence in developing countries: review of prevalence and risk factors. Int Urogynecol J 2011;22(2):127-135.

12. Mallett VT. Female urinary incontinence: what the epidemiologic data tell us. Int J Fertil Womens Med 2005;50(1): 12-17.

13. Fantl JA. Behavioral intervention for community-dwelling individuals with urinary incontinence. Urology 1998;51(2A Suppl):30-34.

14. Townsend MK, Danforth KN, Grodstein F. Incidence and remission of urinary incontinence in middle-aged women. Am J Obstet Gynecol 2007;197(2):167e1-167e5.

15. Singh A, Arora AK. Effect of uterine prolapse on the lives of rural north Indian women. Singapore J Obst Gyn 2003;34(1): 52-58.

16. Kumari S, Walia IJ, Singh AJ. Self reported uterine prolapse in a resettlement colony of North India. J Midwifery and Women's Health 2000;45(4):343-350.

17. Bai SW, Jeon JM, Kim JY et al. Relationship between urinary incontinence and pelvic organ prolapse. Int Urogynecol J 2002;13(4):256-260.

18. Walker GJ, Gunasekera P. Pelvic organ prolapse and incontinence in developing countries: review of prevalence and risk factors. Int Urogynecol J 2011;22(2):127-135.

19. Price N, Dawood R, Jackson SR. Pelvic floor exercise for urinary incontinence: a systematic literature review. European Menopause J 2010;67(4):309-315.

20. Sangsawang B, Sangsawang N. Stress urinary incontinence in pregnant women: a review of prevalence, pathophysiology, and treatment. Int Urology J 2013 June;24(6):901-912.

21. Kaur B. Reproductive health seeking behavior: a study of young females in slum areas of Chandigarh. PhD thesis, Panjab University: Chandigarh; 2004.

22. Kumari S, Jain V, Mandal AK, Singh A. Behavioral therapy for urinary incontinence in India. Int J Gynaecol Obstet 2008; 103(2):125-130. 